\title{
DEVELOPMENT AND ASSESSMENT OF A SINGLE-EVENT DESIGN FLOOD ESTIMATION TOOL: CASE STUDY IN FOUR CLIMATOLOGICAL REGIONS OF SOUTH AFRICA
}

\author{
OCKERT J. GERICKE \\ Unit for Sustainable Water and Environment, Department of Civil Engineering, \\ Central University of Technology, South Africa
}

\begin{abstract}
The estimation of design floods characterised by a specific magnitude-frequency relationship at a particular site is necessary for the planning, design and operation of hydraulic structures. Both the occurrence and the frequency of floods, along with the uncertainty involved in the estimation thereof, contribute to the practitioners' dilemma to make a single, justifiable decision based on the results obtained from the various single-event design flood estimation methods available internationally. This paper presents the further development and assessment of a Design Flood Estimation Tool (DFET) in four climatologically different regions of South Africa. The DFET was developed and programmed using Microsoft Visual Basic for Applications and the functionality and application thereof were assessed by comparing the DFET-based probabilistic, deterministic and empirical design flood estimates in 12 gauged catchments. The refined and improved DFET proved to be an easy to use software tool for the rapid estimation and assessment of alternative design flood estimation methods for at-site applications in both gauged and ungauged catchments. In general, the empirical methods resulted in more acceptable design flood peaks than the deterministic methods when compared to the at-site probabilistic flood peaks. Furthermore, the use of more complex deterministic methods, e.g. Synthetic Unit Hydrograph (SUH) method, as opposed to the more simplified deterministic methods, e.g. Rational method (RM) and Soil Conservation Services (SCS) method, does not necessarily guarantee and result in more acceptable peak discharge estimates. The latter also emphasises that no single design flood estimation method could be regarded as superior to any other method when the wide range of flood magnitude-frequency problems encountered in practice, needs to be solved. Practitioners still have to apply their own experience, knowledge and skills to these particular problems until the current National Flood Study Programme (NFSP) narrows the gap between flood research and practice in South Africa.
\end{abstract}

Keywords: design flood, design rainfall, estimation, flood magnitude-frequency, flood modelling.

\section{INTRODUCTION}

The estimation of design floods characterised by a specific magnitude-frequency relationship at a particular site is necessary for the planning, design and operation of hydraulic structures [1]. Both the occurrence and frequency of floods, along with the uncertainty involved in the estimation thereof, contribute to the practitioners' dilemma to make a single, justifiable decision based on the results obtained from the various single-event design flood estimation methods available internationally [2].

In South Africa, three basic approaches to design flood estimation are available, e.g. probabilistic, deterministic and empirical methods [3], [4]. Apart from the probabilistic methods, there is no guarantee that any of the deterministic and/or empirical methods would result in more acceptable flood magnitude-frequency relationships. Hence, in order to assess the uncertainty in using the latter design flood estimation methods, all approaches should be included in any specific design situation and not be limited to using only the more simplified methods, e.g. the +160 -year old Rational method [2]. In order to overcome some of the 
inherent limitations of the current available methods and to enhance the practitioners' decision-making process, in conjunction with the overall objective of the National Flood Studies Programme (NFSP) in South Africa [5] to update and enhance design flood estimation methodologies, the Utility Programs for Drainage (UPD) software [6], [7] and Design Flood Estimation Tool (DFET) [2] were developed and are frequently updated.

The overall objective of this paper is to present the further development and assessment of the DFET in 12 gauged catchments located in four climatologically different regions of South Africa. The specific objectives are to: (i) refine and improve the DFET to ensure that it is compatible with other relevant software interfaces and contains the latest design rainfall information, and catchment parameter and design flood estimation methodologies, and (ii) demonstrate the use and functionality of the DFET by assessing the performance of the various design flood estimation methods in different catchment size ranges, e.g. $A<150 \mathrm{~km}^{2}$, $150 \leq A \leq 1,000 \mathrm{~km}^{2}$ and $1,000 \leq A \leq 10,000 \mathrm{~km}^{2}$.

A summary of the study area is included in the next section. Thereafter, the methodologies involved in meeting the objectives are detailed, followed by the results and the discussion thereof. In the conclusion, some concluding remarks are made in terms of the major findings.

\section{STUDY AREA}

South Africa is located on the most southern tip of Africa and demarcated into 22 primary drainage regions (A to $\mathrm{X}$ ) as shown in Fig. 1. These primary drainage regions are further delineated into 148 secondary drainage regions, i.e. A1, A2, to X4 [8]. The 12 gauged catchments in this study are located in 10 of these secondary drainage regions which are located in four distinctive climatological regions of South Africa, i.e. the Northern Region (NR), Central Region (CR), Southern Winter Coastal Region (SWCR), and Eastern Summer Coastal Region (ESCR) [9].

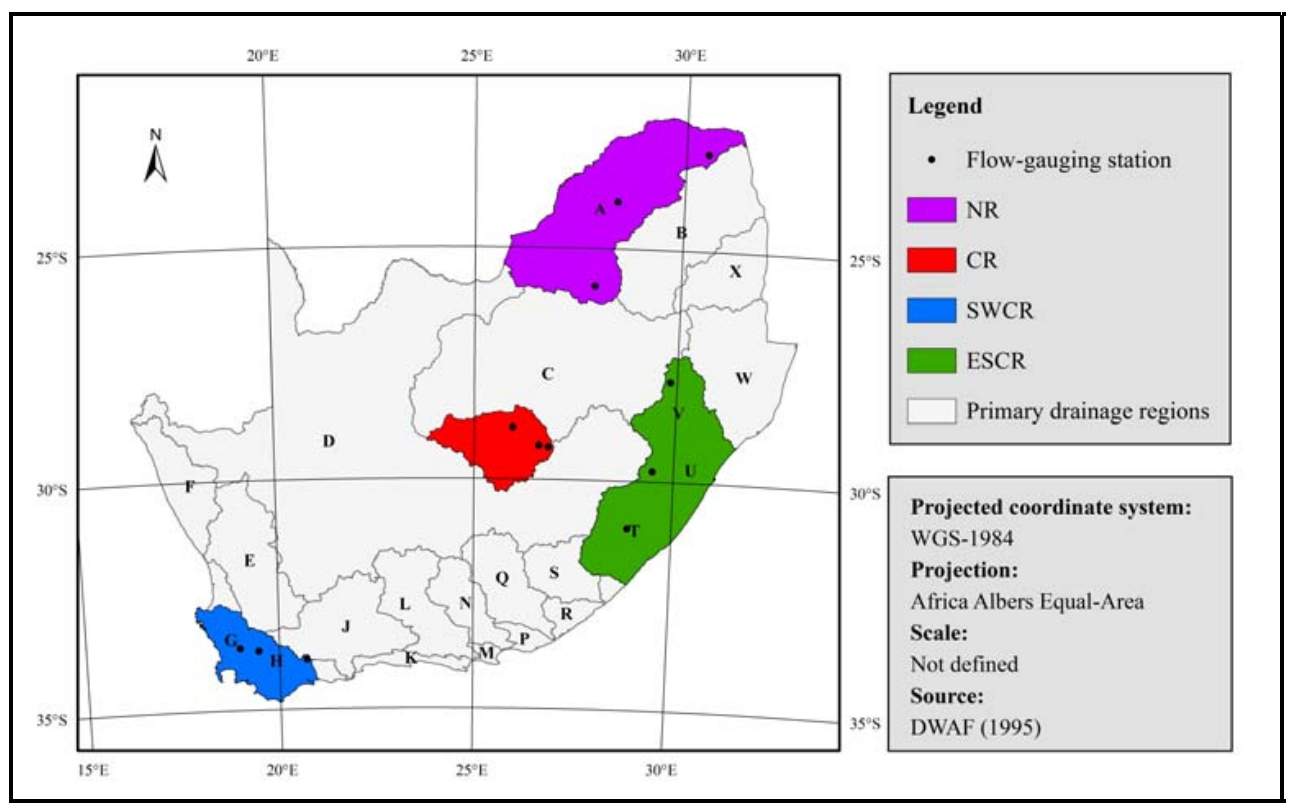

Figure 1: Location of 12 flow-gauging stations within the four climatological regions. (Source: [10].) 
The four climatological regions are representative of the broad variations in climate (e.g. Mean Annual Precipitation (MAP), rainfall type, distribution and rainfall seasonality), catchment geomorphology, channel geomorphology, geographical location, and altitude above mean sea level found in South Africa [9]. The catchment areas range between $28 \mathrm{~km}^{2}$ and $6331 \mathrm{~km}^{2}$ and are regarded as "gauged", since Department of Water and Sanitation (DWS) flow-gauging stations are located at the outlet of each catchment. Table 1 contains a summary of the main geomorphological catchment properties, e.g. MAP, catchment area $(A)$, hydraulic length $\left(L_{H}\right)$, centroid distance $\left(L_{C}\right)$, average catchment slope $(S)$ and main river slope $\left(S_{C H}\right)$.

Table 1: Main geomorphological properties of the 12 catchments in the four climatological regions. (Source: [9].)

\begin{tabular}{|c|c|c|c|c|c|c|c|}
\hline \multirow[b]{2}{*}{ Region } & \multirow[b]{2}{*}{$\begin{array}{l}\text { Catchment } \\
\text { descriptor }\end{array}$} & \multicolumn{6}{|c|}{ Catchment characteristics } \\
\hline & & $\begin{array}{l}\text { MAP } \\
\text { (mm) }\end{array}$ & $\begin{array}{c}A \\
\left(\mathbf{k m}^{2}\right)\end{array}$ & $\begin{array}{c}L_{H} \\
(\mathbf{k m})\end{array}$ & $\begin{array}{c}L_{C} \\
(\mathbf{k m})\end{array}$ & $\begin{array}{c}S \\
(\%)\end{array}$ & $\begin{array}{l}S_{C H} \\
(\%)\end{array}$ \\
\hline \multirow{3}{*}{ NR } & A2H012 & 690 & 2555 & 57.4 & 22.1 & 5.30 & 0.69 \\
\hline & A5H004 & 623 & 636 & 68.4 & 37.4 & 8.73 & 0.71 \\
\hline & A9H003 & 967 & 61 & 16.3 & 10.7 & 15.87 & 1.16 \\
\hline \multirow{3}{*}{$\mathrm{CR}$} & C5R003 & 549 & 937 & 53.8 & 31.1 & 5.04 & 0.27 \\
\hline & C5R004 & 518 & 6331 & 186.7 & 106.4 & 4.19 & 0.13 \\
\hline & C5R005 & 660 & 116 & 16.2 & 7.9 & 5.50 & 0.90 \\
\hline \multirow{3}{*}{ SWCR } & G1H007 & 899 & 724 & 55.5 & 29.0 & 26.21 & 0.46 \\
\hline & H4H006 & 450 & 2878 & 109.9 & 26.9 & 29.21 & 0.47 \\
\hline & H7H004 & 566 & 28 & 15.7 & 7.5 & 31.28 & 4.54 \\
\hline \multirow{3}{*}{ ESCR } & T3H005 & 877 & 2565 & 160.2 & 86.7 & 21.42 & 0.45 \\
\hline & T5H004 & 1060 & 537 & 67.4 & 23.9 & 22.66 & 0.77 \\
\hline & V3H007 & 898 & 129 & 24.9 & 16.9 & 15.73 & 0.93 \\
\hline
\end{tabular}

\section{METHODOLOGY AND RESULTS}

This section presents the methodology adopted to further develop and refine the DFET and the assessment and discussion of the DFET-based design flood estimation results at a catchment level in the four climatologically different regions of South Africa.

\subsection{Development of DFET}

The original DFET [2] was developed and automated using Microsoft Visual Basic for Applications (VBA). The integral part of automation is dependent on the development of the VBA project comprising of a set of modules which contains macros consisting each of a set of declarations followed by procedures or methods acting on toolbar controls. The latter controls are used to receive user input, display output and trigger event procedures.

Both interactive (responsive to user actions) and static (accessible only through code) controls are incorporated in the refined version of the DFET (currently Version 1.3). Both the information processing and application phases of the DFET are now also characterised by a full graphical interface, enabling the printing/plotting of worksheets and graphs, while an improved selection of Geographical Information Systems (GIS)-based maps for easy reference is also available. The DFET was further refined by updating the design rainfall information and methods used to estimate design rainfall. Typically, direct imports from the Regional Linear Moment Algorithm and Scale Invariance (RLMA\&SI) design rainfall software [11], [12] are now possible. The catchment parameter estimations functionalities 
and data imports from GIS-based software were also updated to ensure an improved characterisation of various catchment parameters. For example, extensive GIS-based longitudinal profiles of main watercourses/rivers obtained from Digital Elevation Models (DEMs) in the ArcGIS ${ }^{\mathrm{TM}}$ environment could now be imported into the DFET to enable the rapid estimation of average main watercourse/river slopes using the methods as proposed by [4] and [13], respectively.

The HOME page of the DFET is shown in Fig. 2 and enables the viewing and/or editing of the relevant databases, design tables, design flood estimation methods, GIS-based maps and graphical plots contained in the various worksheets. It also serves as the primary worksheet with click buttons which activate macros to direct or redirect the user to any required worksheet.

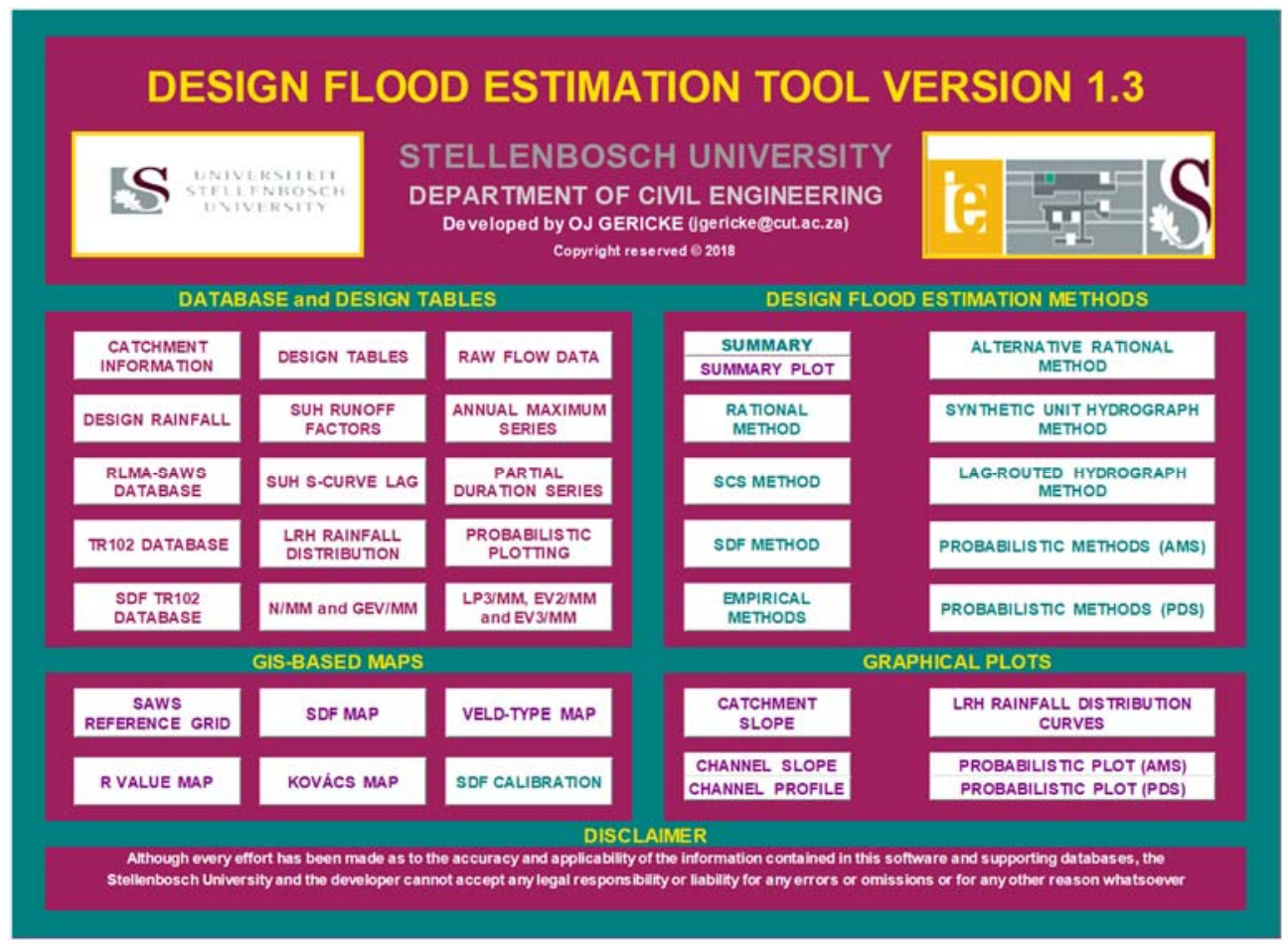

Figure 2: DFET HOME page.

\subsection{Estimation of at-site probabilistic design floods}

At-site probabilistic flood frequency analyses of the annual maximum series (AMS) were conducted using the DFET at the 12 flow-gauging stations to summarise the observed flood peaks, estimate parameters and select appropriate theoretical probability distributions. The observed flood peaks were summarised by ranking the AMS in a descending order of magnitude and the Cunnane plotting position [7] was used to assign return period (T) values to the plotted values. The Method of Moments (MM) and Linear Moments (LM) were used to estimate parameters to ultimately enable the fitting of theoretical probability distributions to the AMS values. 
The average AMS record length of the 12 catchments is 60 years. The statistical properties of each AMS dataset also confirmed the asymmetrical nature thereof, i.e. a high degree of variability and skewness. Consequently, the General Extreme Value (GEV) and Log-Pearson Type 3 (LP3) probability distributions were regarded as the most suitable distributions in $42 \%$ and $33 \%$ of all the catchments, respectively. The Generalised Logistic (GLO) probability distribution proved to be the most appropriate distribution in the remainder $25 \%$ of the catchments. The DFET-based probabilistic plots at a catchment level in the four climatological regions are shown in Fig. 3.

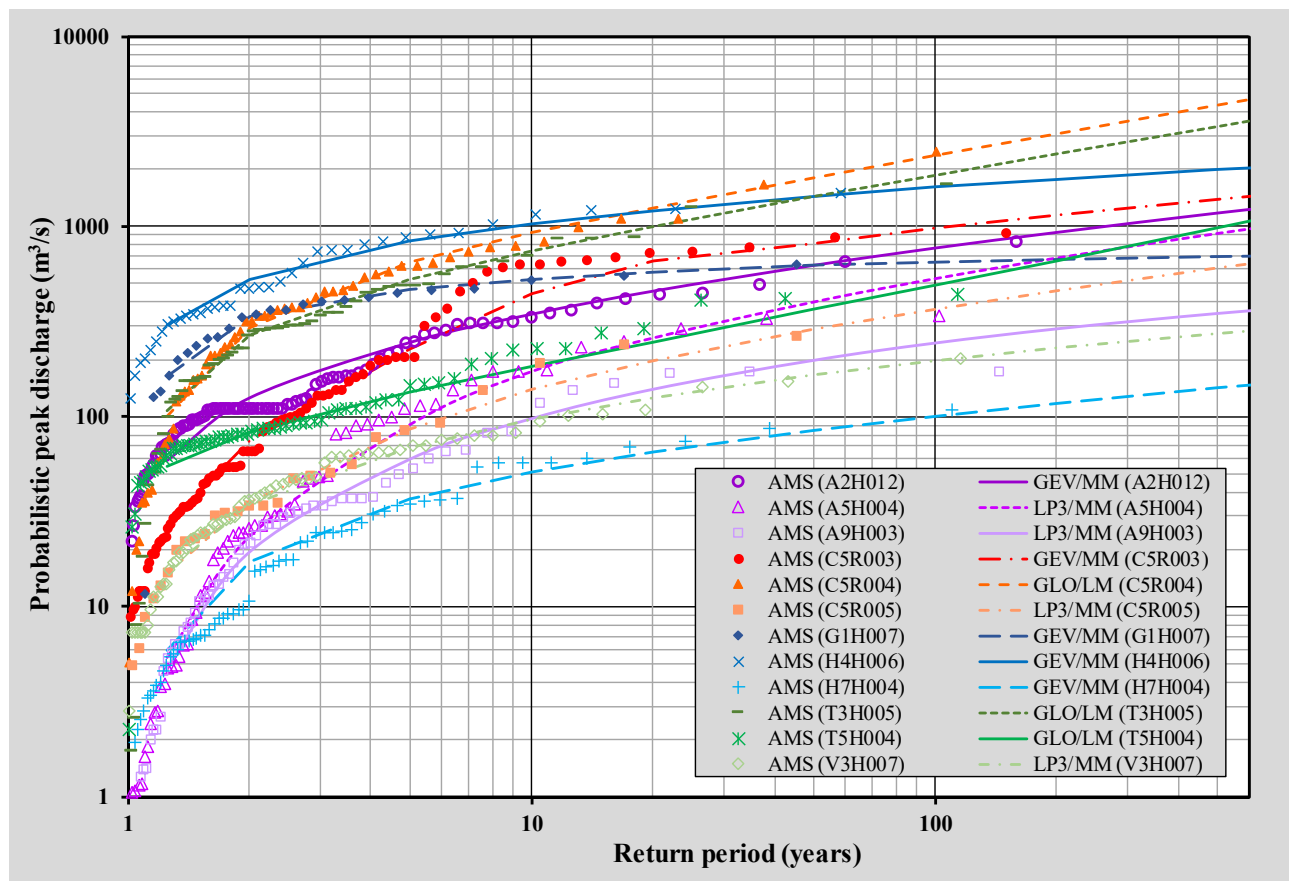

Figure 3: Probabilistic plots $(1 \leq \mathrm{T} \leq 1,000$-year) based on the ranked AMS and Cunnane plotting position in the four climatological regions.

\subsection{Estimation and assessment of deterministic and empirical design floods}

The DFET was used to process all the catchment parameter and design rainfall information to serve as input to the various deterministic and empirical design flood estimation methods. All other design flood calculation procedures are fully automated and the standard procedure and techniques associated with each method were used by default, while taking cognisance of the assumptions, areal limitations and intended application of each method. Both singleevent deterministic (e.g. Rational method (RM), Alternative Rational method (ARM), Soil Conservation Services (SCS), Standard Design Flood (SDF), Synthetic Unit Hydrograph (SUH) and Lag-Routed Hydrograph (LRH)) and empirical (e.g. Midgley and Pitman (MIPI), Catchment Parameter (CAPA) and Regional Maximum Flood (RMF)) design flood estimation methods are included in the DFET. 
The DFET-based design flood estimation results $\left(Q_{D}\right)$ based on both the deterministic and empirical methods compared to the at-site flood frequency analyses $\left(Q_{P}\right)$ for return periods ranging from two to 200 years in each catchment were expressed as peak discharge ratios using eqn (1). The average peak discharge ratios (eqn. (1)) at a catchment level are summarised and shown in Fig. 4. In addition, the Root-Mean-Square-Error (RMSE) estimated using eqn (2) and shown in Fig. 5 was also considered to ensure that the accumulated overand/or underestimations are accounted for, i.e. to highlight the actual size of errors produced by each method, with the objective function to minimise the RMSE to zero.

$$
\begin{gathered}
Q_{T-\text { ratio }}=\left(\frac{Q_{D}}{Q_{P}}\right)-1, \\
R M S E=\sqrt{\frac{\sum_{i=1}^{N}\left(Q_{P i}-Q_{D i}\right)^{2}}{N},}
\end{gathered}
$$

where $Q_{\text {T-ratio }}$ is the peak discharge ratio (positive $=$ overestimation and negative $=$ underestimation), RMSE is the Root-Mean-Square-Error, $Q_{D}$ is the design peak discharge $\left(\mathrm{m}^{3} / \mathrm{s}\right)$ estimated using either a deterministic or empirical method, and $Q_{P}$ is the at-site probabilistic design peak discharge $\left(\mathrm{m}^{3} / \mathrm{s}\right)$.

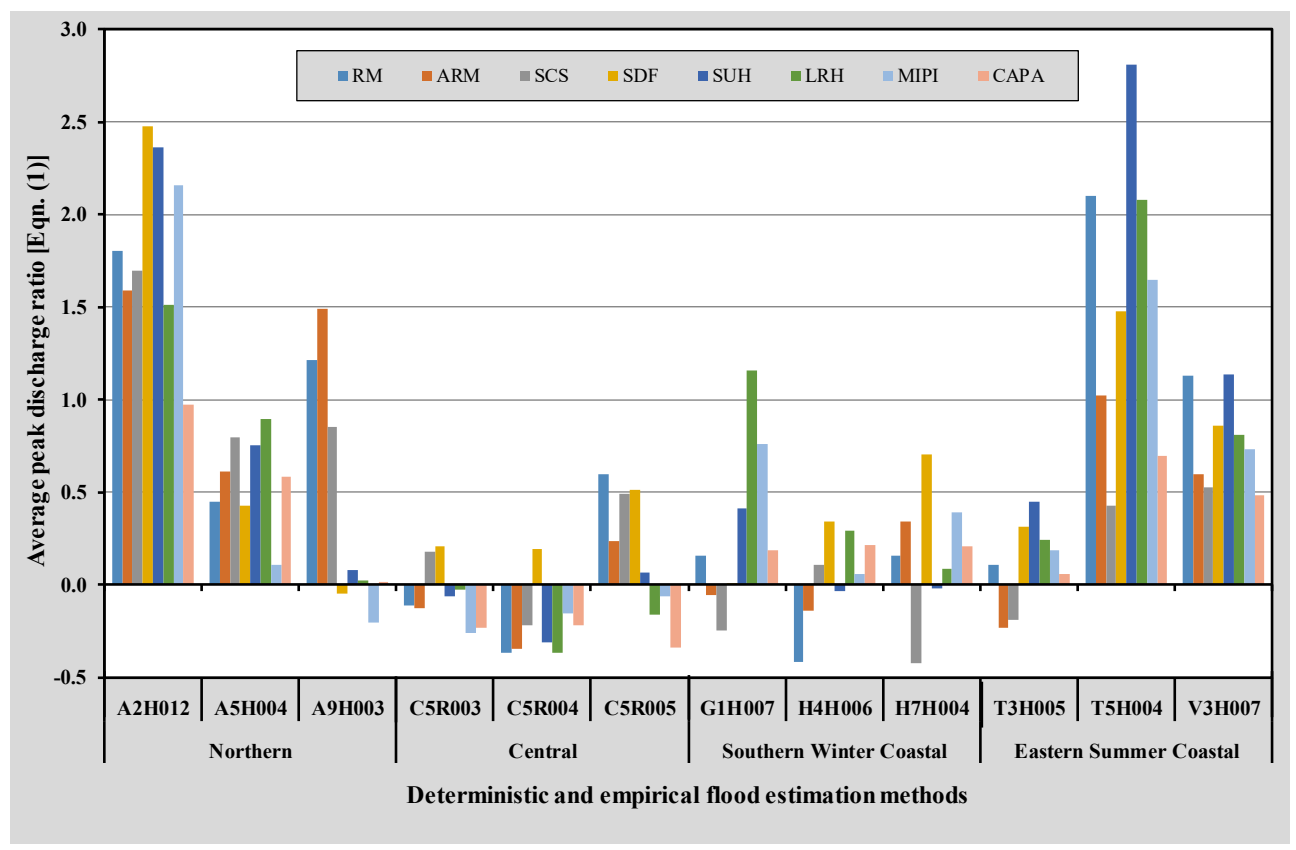

Figure 4: Average peak discharge ratios (eqn (1)) at a catchment level in the four climatological regions. 


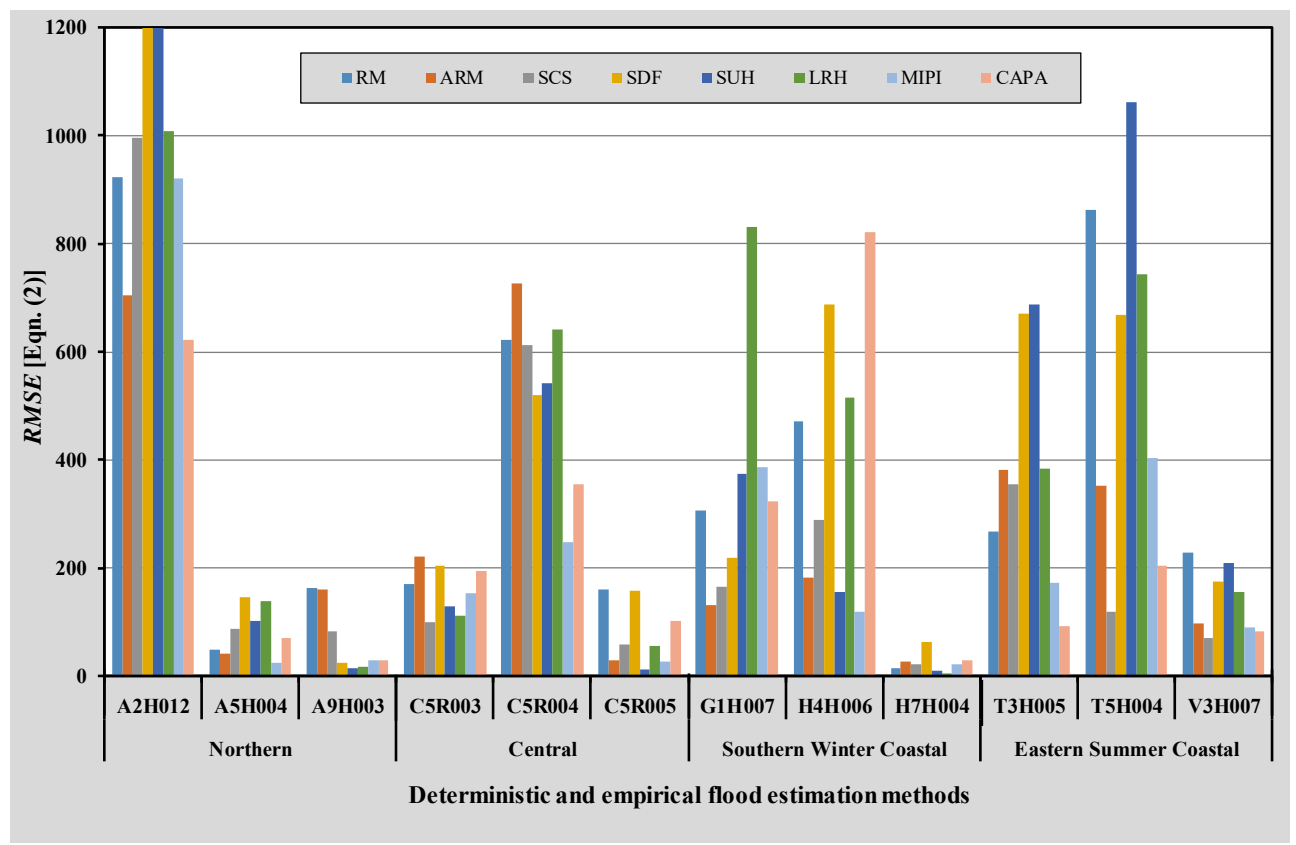

Figure 5: RMSE statistics (eqn (2)) based on the comparison between the probabilistic, deterministic and empirical peak discharges at a catchment level in the four climatological regions.

The results contained in Figs 4 and 5 are indicative of several trends associated with specific catchments and return periods, which are highlighted below:

- Northern Region: On average, the deterministic and empirical flood peaks $\left(Q_{D}\right)$ exceeded the at-site probabilistic flood peaks $\left(Q_{P}\right)$ in both catchments $\mathrm{A} 2 \mathrm{H} 012$ and A5H004, respectively. In catchment A9H003, all the methods also exceeded the $Q_{P}$ values, except for the SDF and MIPI methods. On average, the empirical methods, especially the CAPA method, demonstrated the best results, e.g. 1\%-97\% overestimation, $r^{2} \approx 0.99$, and $30 \leq R M S E \leq 623$.

- Central Region: In this region, the results varied from overestimations to underestimations $<50 \%$. The SDF flood peaks constantly exceeded the at-site probabilistic flood peaks in all the catchments, followed by the SCS method in two catchments. In catchment C5R005, all the deterministic methods, except the LRH method, exceeded the $Q_{P}$ values. In all other cases, the at-site probabilistic flood peaks were underestimated. On average, the MIPI method demonstrated the best results, e.g. $-6 \%--26 \%$ underestimation, $0.93 \leq r^{2} \leq 0.99$, and $26 \leq R M S E \leq 248$.

- Southern Winter Coastal Region: On average, the deterministic flood peaks based on the ARM (catchments G1H007 and H4H006), SCS (catchments G1H007 and H7H004), RM and SUH (catchment H4H006) underestimated the at-site probabilistic flood peaks, while all the other methods resulted in overestimations $\leq 75 \%$. On average, the ARM demonstrated the best results, e.g. $-6 \%-34 \%$ underestimation/overestimation, $0.80 \leq r^{2} \leq 0.83$, and $26 \leq R M S E \leq 183$. 
- Eastern Summer Coastal Region: On average, the deterministic and empirical flood peaks exceeded the at-site probabilistic flood peaks in all the catchments, except for the ARM and SCS methods in catchment T3H005. On average, as in the case of the Northern Region, the CAPA method demonstrated the best results, e.g. $6 \%-70 \%$ overestimation, $r^{2} \approx 0.87$, and $81 \leq R M S E \leq 203$.

Above-listed results highlight a number of important issues that need to be discussed further in the next section.

\section{DISCUSSION}

In most of the catchments, the empirical methods (e.g. MIPI and CAPA) resulted in more acceptable design flood peaks than the deterministic methods when compared to the at-site probabilistic flood peaks. The fact that the empirical methods are less reliant on design rainfall information, site-specific runoff coefficients and catchment response time than the deterministic methods, contributed towards this trend. In essence, this trend highlights that subjectivity could be introduced when design rainfall is estimated using different depthduration-frequency (DDF) relationships in conjunction with specific deterministic design flood estimation methods, e.g. RM and ARM. In the RM, the DDF relationship is based on the 'outdated' methodology proposed by [14], while in the ARM, which resulted in much more acceptable design flood peaks than the RM when compared to the at-site probabilistic flood peaks, the DDF relationship is based on the updated and recent methodology proposed by [11], [12]. Furthermore, the selection of site-specific runoff coefficients or curve numbers, i.e. coefficients representative of the percentage of effective rainfall which is converted into direct runoff, not only introduces more subjectivity and associated uncertainty, but wrongfully also "ignore" the antecedent moisture conditions by being constant for a specific return period. The estimation of catchment response times using empirical equations beyond their region of original development and without applying appropriate adjustment factors to compensate for the local differences in catchment characteristics, further exaggerates the situation. Hence, high runoff coefficients, underestimated time parameters and associated lower design rainfall depths, although of much higher intensities, would result in overestimated peak discharges, while low runoff coefficients and overestimated time parameters would result in underestimates.

\section{CONCLUSIONS}

The overall objective of this study was to present the further development and assessment of the DFET in 12 gauged catchments located in four climatologically different regions of South Africa. In applying the refined and improved DFET to the 12 gauged catchments, it proved to be an easy to use software tool for the rapid estimation and assessment of alternative design flood estimation methods for at-site applications in both gauged and ungauged catchments. In general, the empirical methods resulted in more acceptable design flood peaks than the deterministic methods when compared to the at-site probabilistic flood peaks. Furthermore, the use of more complex deterministic methods, e.g. SUH and LRH, as opposed to the more simplified deterministic methods, e.g. RM and SCS, does not necessarily guarantee and result in more acceptable peak discharge estimates. The latter also emphasises that no single design flood estimation method could be regarded as superior to any other method when the wide range of flood magnitude-frequency problems encountered in practice needs to be solved. Practitioners still have to apply their own experience, knowledge and skills to these particular problems until the current National Flood Study Programme (NFSP) [5] narrows the gap between flood research and practice in South Africa. 


\section{REFERENCES}

[1] Pegram, G.G.S \& Parak, M., A review of the regional maximum flood and rational formula using geomorphological information and observed floods. Water SA, 30(3), pp. 377-392, 2004.

[2] Gericke, O.J. \& Du Plessis, J.A., Development of a customised design flood estimation tool to estimate floods in gauged and ungauged catchments. Water SA, 39(1), pp. 6794, 2013. DOI: 10.4314/wsa.v39i1.9.

[3] Smithers, J.C., Review: Methods for design flood estimation in South Africa. Water SA, 38(4), pp. 633-646, 2012.

[4] Van der Spuy, D. \& Rademeyer, P.F., Flood Frequency Estimation Methods as Applied in the Department of Water and Sanitation, DWS: Pretoria, RSA, 2018.

[5] Smithers, J.C., Görgens, A.H.M., Gericke, O.J., Jonker, V. \& Roberts, P., The Initiation of a National Flood Studies Programme for South Africa, SANCOLD: Pretoria, RSA, 2014.

[6] Van Dijk, M., Utility Programs for Drainage (UPD), Sinotech CC: Pretoria, RSA, 2005. www.sinotechcc.co.za/Software/UPD/. Accessed on: 15 Mar. 2012.

[7] SANRAL, Drainage Manual, 6th ed., South African National Roads Agency Limited: Pretoria, RSA, 2013.

[8] Midgeley, D.C., Pitman, W.V. \& Middleton, B.J., Surface Water Resources of South Africa, WRC Report No. 298/2/94. Water Research Commission: Pretoria, RSA, 1994.

[9] Gericke, O.J., Catchment response time and design rainfall: The key input parameters for design flood estimation in ungauged catchments. Journal of the South African Institution of Civil Engineering, 58(1), pp. 2-15, 2018. DOI: 10.17159/2309-8775/ 2018/v60n4a6.

[10] DWAF, GIS Data: Drainage Regions of South Africa, Department of Water Affairs and Forestry: Pretoria, RSA, 1995.

[11] Smithers, J.C. \& Schulze, R.E., Design Rainfall and Flood Estimation in South Africa, WRC Report No. 1060/01/03. Water Research Commission: Pretoria, RSA, 2003.

[12] Smithers, J.C. \& Schulze, R.E., The estimation of design rainfall for South Africa using a regional scale invariant approach. Water SA, 30(4), pp. 435-444, 2004.

[13] Gericke, O.J. \& Du Plessis, J.A., Catchment parameter analysis in flood hydrology using GIS applications. Journal of the South African Institution of Civil Engineering, 54(2), pp. 15-26, 2012.

[14] Midgeley, D.C. \& Pitman, W.V., A Depth-Duration-Frequency Diagram for Point Rainfall in Southern Africa, HRU Report No. 2/78. University of the Witwatersrand, Hydrological Research Unit: Johannesburg, RSA. 1978. 